\title{
Exposure to Bisphenol A, Bisphenol F, and Bisphenol S in U.S. Adults and Children: The National Health and Nutrition Examination Survey 2013-2014
}

\author{
Hans-Joachim Lehmler, ${ }^{\dagger}$ Buyun Liu, ${ }^{\ddagger}$ Manuel Gadogbe, ${ }^{\dagger}$ and Wei Bao ${ }^{*} \neq$ (우
}

${ }^{\dagger}$ College of Public Health, Department of Occupational \& Environmental Health, and ${ }^{\ddagger}$ College of Public Health, Department of Epidemiology, University of Iowa, 145 N. Riverside Drive, Iowa City, Iowa 52242, United States

\section{Supporting Information}

ABSTRACT: Bisphenol F (BPF) and bisphenol S (BPS) are replacing bisphenol $\mathrm{A}(\mathrm{BPA})$ in the manufacturing of products containing polycarbonates and epoxy resins. Data on current human exposure levels of these substitutes are needed to aid in the assessment of their human health risks. This study analyzed urinary bisphenol levels in adults $(N=1808)$ and children $(N=868)$ participating in the National Health and Nutrition Examination Survey (NHANES) 2013-2014 and investigated demographic and lifestyle factors associated with urinary levels of bisphenols. BPA, BPS, and BPF were detected in $95.7,89.4$, and $66.5 \%$ of randomly selected urine samples analyzed as part of NHANES 2013-2014, respectively. Median levels of BPA in U.S. adult were higher (1.24 $\mu \mathrm{g} / \mathrm{L})$ than BPF and BPS levels (0.35 and $0.37 \mu \mathrm{g} / \mathrm{L}$, respectively). For children, median BPA levels were also higher $(1.25 \mu \mathrm{g} / \mathrm{L})$ than BPF and BPS levels (0.32 and $0.29 \mu \mathrm{g} / \mathrm{L}$, respectively). The limits of detection for BPA, BPF, and BPS were $0.2,0.2$, and $0.1 \mu \mathrm{g} / \mathrm{L}$, respectively. Urinary levels showed associations with gender, race/ethnicity, family income, physical activity, smoking, and/or alcohol intake that depended on the specific bisphenol. The results of this study indicate that exposure of the general U.S. population to BPA substitutes is almost ubiquitous. Because exposures differ across the U.S. population, further studies of environmental, consumer, and lifestyle factors affecting BPF and BPS exposures are warranted.

\section{INTRODUCTION}

Bisphenol A (BPA) (4,4' -(propane-2,2-diyl)diphenol) is a highvolume industrial chemical, with a global consumption of approximately 7.7 million metric tons in 2015, and the global BPA demand is projected to increase to 10.6 million metric tons by 2022. ${ }^{1}$ BPA is used for the manufacturing of polycarbonates and epoxy resins as well as various low-volume specialty applications. ${ }^{2,3}$ Because of growing human health concerns, the use of BPA-based plastics in food and beverage applications is under scrutiny. The use of BPA in baby bottles is now prohibited in Canada, the European Union, and the United States. ${ }^{4-6}$ The European Chemical Agency (ECHA) added BPA in 2017 to the Candidate List of substances of very high concern. Because of the concern about its potential toxicity in humans, BPA is increasingly replaced by structurally similar chemicals, in particular bisphenol $\mathrm{F}$ (BPF) $\left(4,4^{\prime}\right.$ dihydroxydiphenyl-methane) and bisphenol S (BPS) (4,4'sulfonylbisphenol), in the manufacturing of polycarbonates and epoxy resins. BPF and BPS are also used in a variety of common consumer products, for example, thermal paper. ${ }^{7}$ According to ECHA, 1000 to 10000 million metric tons of BPS are manufactured or imported annually into the European Economic Area. No production data for BPF are currently registered with ECHA, suggesting that BPF is still a low use chemical, at least in Europe.
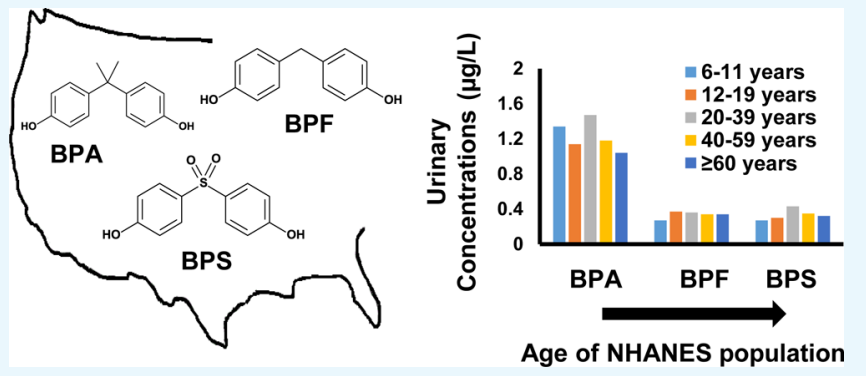

BPA, BPF, and BPS have been detected in many environmental samples, including soil, sediments, water, sewage effluents, and sewage sludge. 9 They have a comparatively low octanol-water coefficient $\left(\log K_{\text {ow }}<5\right)$, are readily biotransformed in the environment, and do not bioaccumulate and biomagnify in aquatic and terrestrial food chains. ${ }^{3,9,10}$ BPA typically is the most prevalent bisphenol analogue in the environment; however, BPF and BPS are also frequently detected in environmental samples from around the world. Bisphenol analogues are present in a broad range of consumer products and in foodstuffs, with BPA and BPF being major contaminants present in foods from the United States. ${ }^{11} \mathrm{BPF}$ is also a natural product present in mustard. ${ }^{12}$ Environmental exposure of humans to BPA and its substitutes (e.g., BPF) occurs via the diet. ${ }^{9,13,14}$ Dermal exposure to personal care and other consumer products, ingestion of household dust, and inhalation represent additional routes of exposure to bisphenols. ${ }^{15-18}$ Dermal contact with products containing bisphenols, such as handling thermal receipt paper, represents a source of occupational exposure to BPA and its substitutes. ${ }^{19}$

Received: April 26, 2018

Accepted: May 30, 2018

Published: June 18, 2018 
Table 1. Urinary Concentrations of BPA, BPF, and BPS in U.S. Adults in NHANES 2013-2014 ${ }^{a}$

\begin{tabular}{|c|c|c|c|c|c|c|c|c|}
\hline & & & $\mathrm{BPA}, \mu \mathrm{g} / \mathrm{L}$ & & $\mathrm{BPF}, \mu \mathrm{g} / \mathrm{L}$ & & $\mathrm{BPS}, \mu \mathrm{g} / \mathrm{L}$ & \\
\hline & & $N$ & median $(P 25-P 75)$ & $P$ & median $(P 25-P 75)$ & $P$ & median $(P 25-P 75)$ & $P$ \\
\hline all & & 1808 & $1.24(0.57-2.49)$ & & $0.35(0.14-1.11)$ & & $0.37(0.14-0.88)$ & \\
\hline age & $20-39$ years & 598 & $1.47(0.70-2.93)$ & $<0.001$ & $0.36(0.14-1.29)$ & 0.86 & $0.43(0.17-0.96)$ & 0.64 \\
\hline & $40-59$ years & 607 & $1.18(0.52-2.29)$ & & $0.34(0.14-0.95)$ & & $0.35(0.12-0.77)$ & \\
\hline & $\geq 60$ years & 603 & $1.04(0.49-2.26)$ & & $0.34(0.14-1.11)$ & & $0.32(0.13-0.88)$ & \\
\hline gender & male & 851 & $1.39(0.68-2.79)$ & 0.002 & $0.41(0.14-1.30)$ & 0.03 & $0.41(0.16-0.92)$ & 0.08 \\
\hline & female & 957 & $1.09(0.49-2.26)$ & & $0.29(0.14-0.93)$ & & $0.33(0.12-0.85)$ & \\
\hline race/ethnicity ${ }^{b}$ & non-Hispanic white & 757 & $1.22(0.53-2.38)$ & 0.007 & $0.39(0.14-1.21)$ & 0.40 & $0.33(0.12-0.74)$ & 0.001 \\
\hline & Hispanic & 702 & $1.27(0.66-2.55)$ & & $0.23(0.14-0.64)$ & & $0.47(0.21-0.96)$ & \\
\hline & non-Hispanic black & 383 & $1.82(0.87-3.59)$ & & $0.41(0.14-1.42)$ & & $0.62(0.25-1.58)$ & \\
\hline & other & 266 & $0.89(0.39-1.72)$ & & $0.24(0.14-0.78)$ & & $0.29(0.13-0.73)$ & \\
\hline education $^{c}$ & $\begin{array}{l}\text { less than high } \\
\text { school }\end{array}$ & 429 & $1.30(0.68-2.59)$ & 0.93 & $0.28(0.14-1.10)$ & 0.20 & $0.48(0.17-1.05)$ & 0.32 \\
\hline & high school & 406 & $1.30(0.59-2.63)$ & & $0.39(0.14-1.27)$ & & $0.38(0.17-0.91)$ & \\
\hline & college or higher & 973 & $1.21(0.54-2.39)$ & & $0.35(0.14-1.06)$ & & $0.34(0.12-0.78)$ & \\
\hline family $\mathrm{IPR}^{d}$ & $\leq 1.30$ & 574 & $1.47(0.68-2.91)$ & 0.08 & $0.31(0.14-0.87)$ & 0.09 & $0.44(0.16-1.00)$ & 0.32 \\
\hline & $1.31-3.50$ & 564 & $1.18(0.53-2.48)$ & & $0.43(0.14-1.43)$ & & $0.39(0.16-0.94)$ & \\
\hline & $>3.50$ & 514 & $1.18(0.52-2.33)$ & & $0.33(0.14-1.08)$ & & $0.30(0.10-0.73)$ & \\
\hline & missing & 156 & $1.21(0.68-2.26)$ & & $0.26(0.14-0.84)$ & & $0.39(0.21-0.83)$ & \\
\hline smoking $^{e}$ & never smoker & 1028 & $1.15(0.54-2.36)$ & 0.06 & $0.30(0.14-1.04)$ & 0.44 & $0.35(0.12-0.81)$ & 0.07 \\
\hline & current smoker & 365 & $1.43(0.61-3.07)$ & & $0.40(0.14-1.13)$ & & $0.45(0.17-1.01)$ & \\
\hline & ever smoker & 415 & $1.33(0.59-2.61)$ & & $0.40(0.14-1.20)$ & & $0.35(0.15-0.90)$ & \\
\hline Physical activity, MET & $<600$ & 767 & $1.15(0.48-2.37)$ & 0.84 & $0.38(0.14-1.15)$ & 0.99 & $0.36(0.14-0.80)$ & 0.81 \\
\hline & $600-1200$ & 206 & $1.05(0.56-2.11)$ & & $0.33(0.14-1.23)$ & & $0.39(0.12-1.02)$ & \\
\hline & $>1200$ & 835 & $1.38(0.65-2.65)$ & & $0.33(0.14-0.98)$ & & $0.38(0.14-0.88)$ & \\
\hline alcohol intake ${ }^{g}$ & nondrinker & 1245 & $1.23(0.54-2.47)$ & 0.32 & $0.34(0.14-1.17)$ & 0.48 & $0.37(0.14-0.85)$ & 0.03 \\
\hline & moderate drinker & 136 & $1.25(0.68-1.86)$ & & $0.41(0.14-0.97)$ & & $0.26(0.09-0.67)$ & \\
\hline & heavy drinker & 269 & $1.37(0.63-2.93)$ & & $0.32(0.14-1.10)$ & & $0.36(0.16-1.05)$ & \\
\hline & missing & 158 & $1.04(0.61-2.08)$ & & $0.34(0.14-0.89)$ & & $0.50(0.19-1.05)$ & \\
\hline
\end{tabular}

${ }^{a}$ All variables were adjusted using population weights for the sample in which BPA concentration was measured except $N$ (unweighted sample size). ANOVA was used to compare differences of urinary concentrations of BPA, BPF, and BPS among various categorical variables. The analysis of creatinine-adjusted concentrations of BPA, BPS, and BPF is presented in Table S2, Supporting Information. ${ }^{b}$ Race/ethnicity was categorized based on self-reported data into Hispanic (including Mexican and non-Mexican Hispanic), non-Hispanic white, non-Hispanic black, and other race/ ethnicity. ${ }^{37}$ Self-reported education was grouped as less than high school, high school, and college or higher. ${ }^{37}{ }^{d}$ Family IPRs were categorized as $\leq 1.30,1.31-3.50$, and $>3.50 .{ }^{37,50}{ }^{e}$ Self-reported smoking was classified as never smokers who smoked less than 100 cigarettes in their lifetime; current smokers who currently smoke cigarettes; and ever smokers who smoked more than 100 cigarettes in their lifetime but do not smoke

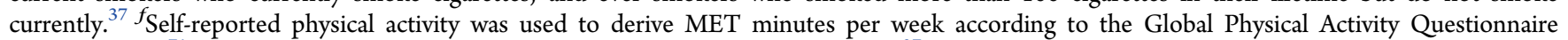

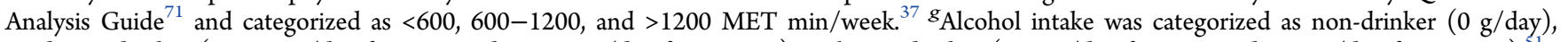
moderate drinker $(0.1-28 \mathrm{~g} /$ day for men and $0.1-14 \mathrm{~g} /$ day for women $)$, or heavy drinker $\left(\geq 28 \mathrm{~g} /\right.$ day for men and $\geq 28 \mathrm{~g} / \mathrm{day}$ for women). ${ }^{51}$

BPA, BPF, and BPS are rapidly metabolized to the corresponding glucuronides by mammalian uridine 5 '-diphosphate-glucuronosyltransferases (UGTs). ${ }^{20,21}$ As has been shown for BPA, these glucuronides are rapidly eliminated with urine in rats and humans. ${ }^{22-24}$ Total urinary levels, typically determined after deconjugation with $\beta$-glucuronidase/ sulfatase, are considered to be a robust biomarker for exposure to bisphenols. ${ }^{25} \mathrm{BPA}$ is ubiquitous in humans and, for example, was detected in earlier studies in $>92 \%$ urine samples from the U.S. population. $^{26-28}$ The limits of detection (LODs) for BPA, $\mathrm{BPS}$, and BPF were $\leq 0.4 \mu \mathrm{g} / \mathrm{L}$ in these studies. ${ }^{26-28} \mathrm{BPA}$ and its metabolites have also been detected in human serum, placental tissue, cord blood, and breast milk. ${ }^{29}$ A human biomonitoring study reported lower detection frequencies for BPS (42 to 91\%) in urine from several Asian countries compared to those of BPA. ${ }^{30}$ Japan and the U.S. were exceptions, with detection frequencies of BPS in urine of 100 and $97 \%$, respectively.

Several other studies also suggest that urinary levels of BPS and $\mathrm{BPF}$ are currently lower compared to that of BPA. ${ }^{28,30-32}$
For example, median concentrations of BPS in urine samples from the Asian countries including China, India, Japan, Korea, Kuwait, Malaysia, and Vietnam were 1 order of magnitude lower than the median concentrations reported for BPA in the same set of samples, with the exception of samples from Japan. ${ }^{30}$ Geometric means of urinary levels of BPF and BPS were at least 3 and 30 times lower than those reported for BPA in adults (age 26-84 years, $N=94$ ) from South China. ${ }^{31}$ Detection frequencies of $79.2 \%$ for BPA, $67.8 \%$ for BPS, and $40.2 \%$ for BPF were observed in urine samples from pregnant women from the Netherlands $(N=1396)$ collected in 20042005 (LODs $<0.18 \mu \mathrm{g} / \mathrm{L}$ ). ${ }^{32}$ Median levels of BPS and BPF were lower compared to that of BPA in this study population. Studies quantifying BPF and BPS in other human compartments are limited, and both bisphenol analogues have relatively small detection frequencies in human serum and breast milk. 19,33,34 Taken together, the presence of BPA substitutes in humans raises questions about their adverse human health effects. 
Evidence from epidemiological and animal studies implicates BPA in sex-specific adverse outcomes, including effects on the brain, immune system, reproductive system, and metabolic processes. $^{3,35,36}$ Significantly less information about potential adverse health outcomes is available about BPF and BPS. Exposure to BPF and BPS was not associated with obesity in the general U.S. population; however, higher exposure to BPS may be associated with greater body mass index and waist circumference. ${ }^{37}$ Urinary levels of both BPA and BPS were strongly correlated with oxidative stress, as determined using 8hydroxy-2'-deoxyguanosine urine levels, in a population from Saudi Arabia exposed highly to BPS. ${ }^{38}$ BPA, but not BPF, was positively associated with thyroid-stimulating hormone in a case-control study from Cyprus and Romania investigating an association between bisphenol exposure and thyroid nodular disease. ${ }^{39}$ Evidence from in vitro and in vivo laboratory studies provides a mechanistic basis for a link between BPF and BPS exposure and adverse health outcomes, such as obesity, in humans: Similar to BPA, BPF and BPS are endocrinedisrupting chemicals and display hormonal activity, with similar average estrogenic, androgenic, and antiestrogenic potencies across different in vitro assays. ${ }^{40-42}$ Both BPF and BPS differentially affect signaling pathways involved in lipid metabolism and adipogenesis ${ }^{43,44}$ and cause DNA damage. ${ }^{42}$

Previous population-based studies with human biomonitoring data have mainly focused on BPA. For BPA substitutes, including BPF and BPS, available data were based on convenience samples, rather than representative samples, ${ }^{28,30}$ or focus on a specific, at-risk population, such as pregnant women. ${ }^{32}$ It is therefore imperative to know the current exposure status of BPF and BPS in a sample that is representative of the entire U.S. population, including children and adolescents, and to characterize the difference in the levels of these environmental phenols depending on population characteristics and lifestyle factors. The present study, for the first time, reports urinary levels of total BPA, BPF, and BPS in the U.S. population by using the nationally representative data from the National Health and Nutrition Examination Survey (NHANES) 2013-2014. Demographic and lifestyle factors associated with urinary levels of all three bisphenols were analyzed as well. The results of this analysis demonstrate both similarities and differences in contemporary exposure of the U.S. population to BPA and its substitutes that warrant further attention.

\section{RESULTS AND DISCUSSION}

Detection Frequency and Levels of Urinary BPA, BPF, and BPS. BPA was found in nearly all urine samples analyzed as part of NHANES 2013-2014, with a detection frequency of $95.7 \%$. This number is comparable to detection frequencies reported in earlier studies of the general U.S. population. ${ }^{26-28}$ The LODs for BPA in these earlier studies were comparable to the LOD in this study and ranged from 0.1 to $0.4 \mu \mathrm{g} / \mathrm{L}$. Detection frequencies of BPA ranged from 74 to $99 \%$ in archived urine samples from U.S. adults $(N=616)$ collected between 2000 and 2014. ${ }^{28}$ The lowest detection frequency in this earlier study (74\%) was observed in samples collected in 2014. In our study, detection frequencies of BPS and BPF were 89.4 and $66.5 \%$ in urine from U.S. adults, respectively. The lower detection frequencies of both substitutes compared to BPA are consistent with earlier, small-scale biomonitoring studies in the U.S. and other countries. ${ }^{28,30}$ The LODs for BPF and BPS in the earlier studies were $\leq 0.1 \mu \mathrm{g} / \mathrm{L}^{28,30}$ In urine samples collected in 2004-2005 from pregnant women from the Netherlands $(N=1396)$, detection frequencies of BPA (79.2\%) were also higher compared to the detection frequencies of BPS (67.8\%) and BPF (40.2\%). ${ }^{32}$ Only limited information regarding time trends in the levels of BPS and BPF in humans is currently available. Detection frequencies for BPF ranged from 42 to $88 \%$ in urine samples from U.S. adults collected between 2000 and 2014 and showed no clear trend with time. ${ }^{28}$ In the same study, BPS had the lowest detection frequencies (19-74\%) of all three bisphenols. Unlike those of $\mathrm{BPF}$, detection frequencies of BPS in the urine from U.S. adults increased from 2000 to $2014{ }^{28}$ Because BPA, BPF, and BPS are glucuronidated by human UGTs ${ }^{20,21,53}$ and, as has been shown for BPA, rapidly excreted with the urine, ${ }^{23}$ their high detection frequencies in spot urine samples from the NHANES population indicate that the general U.S. population is continuously exposed to all three bisphenols.

Median urinary levels of BPA in the adult U.S. population $(N$ $=1808$ ) were $1.24 \mu \mathrm{g} / \mathrm{L}$ (interquartile range, $0.57-2.49 \mu \mathrm{g} / \mathrm{L}$ ) (Table 1). Median urinary levels of BPF and BPS were $0.35 \mu \mathrm{g} /$ $\mathrm{L}(0.14-1.11 \mu \mathrm{g} / \mathrm{L})$ and $0.37 \mu \mathrm{g} / \mathrm{L}(0.14-0.88 \mu \mathrm{g} / \mathrm{L})$, respectively. For comparison, creatinine-adjusted median urinary levels of BPA and its substitutes in adults were 1.20 $\mu \mathrm{g} / \mathrm{g}$ creatinine $(0.73-2.09 \mu \mathrm{g} / \mathrm{g}$ creatinine) for BPA, $0.46 \mu \mathrm{g} /$ $\mathrm{g}$ creatinine $(0.21-1.06 \mu \mathrm{g} / \mathrm{g}$ creatinine $)$ for BPF, and $0.39 \mu \mathrm{g} /$ g creatinine $(0.21-0.84 \mu \mathrm{g} / \mathrm{g}$ creatinine) for BPS (Table S2). The BPA levels observed in our analysis of NHANES 20132014 data for the adult U.S. population are of the same order of magnitude as the levels observed in other studies. For example, a geometric mean BPA level of $2.6 \mu \mathrm{g} / \mathrm{L}$ has been reported for the NHANES 2003-2004 cycle. $^{26}$ An examination of convenience urine samples of U.S. adults showed a significant decrease in urinary levels of total BPA from $2.07 \mu \mathrm{g} / \mathrm{L}$ in 2010 to $0.36 \mu \mathrm{g} / \mathrm{L}$ in $2014,{ }^{28}$ which is consistent with the global phaseout of BPA in food packaging, thermal paper, and other consumer products that contribute to human exposure. ${ }^{54,55}$ Urinary levels of BPA in the NHANES 2013-2014 population are also within the range of concentrations reported for several other countries. For example, the 2007-2009 Canadian Health Measures Survey reported geometric mean urinary BPA levels ranging from 0.82 to $1.49 \mu \mathrm{g} / \mathrm{L}$ for the adult Canadian population. ${ }^{56}$ Geometric mean levels of BPA in urine samples collected from 2010 to 2013 in several European and Asian countries ranged from $0.84 \mu \mathrm{g} / \mathrm{L}$ in Japan to $1.59 \mu \mathrm{g} / \mathrm{L}$ in India. ${ }^{31,57,58}$ In a study of pregnant women from the Netherlands, median levels of BPA were $1.66 \mu \mathrm{g} / \mathrm{L}(0.72-$ $3.56 \mu \mathrm{g} / \mathrm{L})$ in urine samples collected in 2004-2005 $(N=$ $1396) .^{32}$ Levels of $2.99 \mu \mathrm{g} / \mathrm{L}(0.233-27.6 \mu \mathrm{g} / \mathrm{L} ; N=116)$ were reported for a more highly exposed population living near an Ewaste-dismantling area in China. ${ }^{59}$

Information about urinary levels of BPF and BPS is much more limited compared to that of BPA. A study in pregnant women from the Netherlands reported median levels of 0.36 $\mu \mathrm{g} / \mathrm{L}(0.17-1.08 \mu \mathrm{g} / \mathrm{L} ; N=1396)$ for BPS and $0.57 \mu \mathrm{g} / \mathrm{L}$ for BPF $(0.30-1.29 \mu \mathrm{g} / \mathrm{L} ; N=1396) .{ }^{32}$ Median BPF levels of $0.365 \mu \mathrm{g} / \mathrm{L}$ ( $<\mathrm{LOD}$ to $8.68 \mu \mathrm{g} / \mathrm{L} ; N=116)$ were observed in a Chinese population living near an E-waste-dismantling area. ${ }^{59}$ These levels are comparable to the levels observed in the adult NHANES 2013-2014 population in this study (Table 1). Median BPS levels in this study $(0.37 \mu \mathrm{g} / \mathrm{L})$ were higher than BPS levels (median $0.191 \mu \mathrm{g} / \mathrm{L}$, <LOD to $21.0 \mu \mathrm{g} / \mathrm{L} ; N=315$ ) observed in urine samples collected from 2010 to 2011 in several Asian countries, including China, India, Korea, Kuwait, 
Table 2. Association of Demographic and Lifestyle Factors in Adults $(N=1808)$ from NHANES 2013-2014 with Urinary BPA, $\mathrm{BPF}$, and BPS Concentrations ${ }^{a}$

\begin{tabular}{|c|c|c|c|c|c|c|c|}
\hline & & \multicolumn{2}{|c|}{ BPA } & \multicolumn{2}{|c|}{$\mathrm{BPF}$} & \multicolumn{2}{|c|}{ BPS } \\
\hline \multicolumn{2}{|l|}{ variable } & $\beta$ coefficient & $P$ & $\beta$ coefficient & $P$ & $\beta$ coefficient & $P$ \\
\hline age & $20-39$ & [ref] & & [ref] & & {$[\mathrm{ref}]$} & \\
\hline & $40-59$ & -0.02 & 0.80 & -0.02 & 0.84 & 0.02 & 0.8 \\
\hline & $\geq 60$ & 0.03 & 0.65 & 0.003 & 0.98 & 0.18 & 0.1 \\
\hline gender & male & {$[\mathrm{ref}]$} & & {$[\mathrm{ref}]$} & & {$[\mathrm{ref}]$} & \\
\hline & female & 0.07 & 0.20 & 0.005 & 0.95 & 0.05 & 0.55 \\
\hline race/ethnicity ${ }^{b}$ & non-Hispanic white & {$[\mathrm{ref}]$} & & {$[\mathrm{ref}]$} & & {$[\mathrm{ref}]$} & \\
\hline & Hispanic & 0.01 & 0.91 & -0.34 & 0.10 & 0.23 & 0.02 \\
\hline & non-Hispanic black & 0.08 & 0.10 & -0.09 & 0.43 & 0.35 & 0.005 \\
\hline & other & -0.07 & 0.42 & -0.31 & 0.06 & 0.14 & 0.24 \\
\hline education $^{c}$ & less than high school & {$[\mathrm{ref}]$} & & {$[\mathrm{ref}]$} & & {$[\mathrm{ref}]$} & \\
\hline & high school & 0.001 & 0.99 & 0.10 & 0.45 & -0.04 & 0.61 \\
\hline & college or higher & -0.07 & 0.45 & -0.05 & 0.73 & -0.10 & 0.32 \\
\hline family $\mathrm{IPR}^{d}$ & $\leq 1.30$ & {$[\mathrm{ref}]$} & & {$[\mathrm{ref}]$} & & {$[\mathrm{ref}]$} & \\
\hline & $1.31-3.50$ & -0.10 & 0.09 & 0.30 & 0.02 & 0.04 & 0.69 \\
\hline & $>3.50$ & -0.14 & 0.01 & 0.18 & 0.054 & -0.05 & 0.65 \\
\hline & missing & -0.08 & 0.53 & 0.11 & 0.61 & 0.10 & 0.52 \\
\hline smoking $^{e}$ & never smoker & {$[\mathrm{ref}]$} & & {$[\mathrm{ref}]$} & & {$[\mathrm{ref}]$} & \\
\hline & current smoker & 0.19 & 0.01 & 0.13 & 0.45 & 0.13 & 0.07 \\
\hline & ever smoker & 0.12 & 0.09 & 0.16 & 0.23 & 0.11 & 0.16 \\
\hline physical activity, MET min/week ${ }^{f}$ & $<600$ & {$[\mathrm{ref}]$} & & {$[\mathrm{ref}]$} & & {$[\mathrm{ref}]$} & \\
\hline & $600-1200$ & 0.02 & 0.75 & 0.07 & 0.56 & 0.01 & 0.93 \\
\hline & $>1200$ & 0.14 & 0.02 & -0.07 & 0.33 & 0.01 & 0.91 \\
\hline alcohol intake $e^{g}$ & nondrinker & {$[\mathrm{ref}]$} & & {$[\mathrm{ref}]$} & & {$[\mathrm{ref}]$} & \\
\hline & moderate drinker & -0.02 & 0.82 & -0.07 & 0.51 & -0.29 & 0.004 \\
\hline & heavy drinker & 0.07 & 0.30 & -0.21 & 0.29 & 0.10 & 0.26 \\
\hline & missing & -0.19 & 0.02 & -0.005 & 0.99 & 0.16 & 0.10 \\
\hline
\end{tabular}

${ }^{a_{1}}$ The analysis of creatinine-adjusted concentrations of BPA, BPS, and BPF is presented in Table S3, Supporting Information. ${ }^{b}$ Race/ethnicity was categorized based on self-reported data into Hispanic (including Mexican and non-Mexican Hispanic), non-Hispanic white, non-Hispanic black, and other race/ethnicity. ${ }^{37}{ }^{c}$ Self-reported education was grouped as less than high school, high school, and college or higher. ${ }^{37}{ }^{d}$ Family IPRs were categorized as $\leq 1.30,1.30-3.50$, and $>3.50 .{ }^{37,50}$ e Self-reported smoking was classified as never smokers who smoked less than 100 cigarettes in their lifetime; current smokers who currently smoke cigarettes; and ever smokers who smoked more than 100 cigarettes in their lifetime but do not smoke

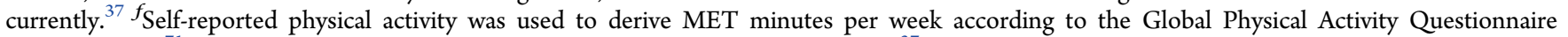
Analysis Guide ${ }^{71}$ and categorized as $<600,600-1200$, and $>1200 \mathrm{MET} \mathrm{min} /$ week. $^{37} \mathrm{~g}_{\mathrm{Alcohol}}$ intake was categorized as non-drinker $(0 \mathrm{~g} / \mathrm{day})$, moderate drinker $(0.1-28 \mathrm{~g} /$ day for men and $0.1-14 \mathrm{~g} /$ day for women $)$, or heavy drinker $\left(\geq 28 \mathrm{~g} /\right.$ day for men and $\geq 28 \mathrm{~g} /$ day for women). ${ }^{51}$

Malaysia, and Vietnam. ${ }^{30}$ Some studies report higher urinary BPS levels compared to the NHANES 2013-2014 data. For example, median levels of BPS were $1.04 \mu \mathrm{g} / \mathrm{L}(N=36)$ in urine from $\mathrm{Japan}^{30}$ and $4.92 \mu \mathrm{g} / \mathrm{L}(N=130)$ in urine from Saudi Arabia. ${ }^{38}$ Although these two studies only investigated a small number of individuals, these findings indicate that, compared to the US, some countries may have significantly higher exposures to BPS because of unique, country-specific environmental factors and consumer behaviors. In the adult U.S. population, BPS showed a slight increase in detection frequency and geometric mean concentration in urine from not calculated in 2010 to $0.25 \mu \mathrm{g} / \mathrm{L}$ in 2014 . $^{28}$ This finding is not surprising because of the replacement of BPA with BPS and other bisphenols in various consumer products. Interestingly, no clear time trend was observed for urinary levels of $\mathrm{BPF},{ }^{28}$ possibly because of the low detection frequency on BPF in urine or because BPF is a natural product present in foodstuff, in particular mustard. ${ }^{12}$

Age, Gender, and Race/Ethnic Differences in Urinary BPA, BPF, and BPS Concentrations in U.S. Adults. BPA levels differed significantly between age groups $(P<0.001$; Table 1); however, no significant differences were observed in the linear regression analysis (Table 2). Urinary levels of BPA showed a trend to increase with age in adult Koreans, with 6069 year old Korean adults having the highest BPA levels, ${ }^{60}$ whereas a decrease in urinary BPA concentrations with age has been reported for the NHANES 2005-2006 population. ${ }^{17}$ Several other biomonitoring studies reported no association between levels of bisphenols in adults and age. ${ }^{32,60-62}$ Overall, associations between urinary levels of BPA and, possibly, its substitutes and age appear to vary in different adult populations, suggesting that more complex environmental factors contribute to adult exposures. Moreover, exposure patterns may change in a population, as suggested by the different age trends of BPA levels observed in the NHANES 2005-2006 ${ }^{17}$ versus NHANES 2013-2014 data (this study).

Urinary levels of BPA $(P=0.002)$ and BPF $(P=0.03)$ were significantly higher in urine samples from male compared to female adults (Table 1). BPS levels were also higher in men than in women; however, this difference did not reach statistical significance $(P=0.08)$. Gender-related differences in urinary levels did not reach statistical significance in the linear regression analysis for any bisphenol investigated (Table 2). Similarly, biomonitoring studies from across the world consistently report that geometric mean urinary levels of BPA in men are higher compared to women; however, these 
Table 3. Urinary Concentrations of BPA, BPF, and BPS in U.S. Children in NHANES 2013-2014

\begin{tabular}{|c|c|c|c|c|c|c|c|c|}
\hline \multirow{2}{*}{\multicolumn{2}{|c|}{ variable }} & \multirow{3}{*}{$\frac{N}{868}$} & \multicolumn{2}{|l|}{$\mathrm{BPA}, \mu \mathrm{g} / \mathrm{L}$} & \multicolumn{2}{|c|}{$\mathrm{BPF}, \mu \mathrm{g} / \mathrm{L}$} & \multicolumn{2}{|l|}{$\mathrm{BPS}, \mu \mathrm{g} / \mathrm{L}$} \\
\hline & & & \multirow{2}{*}{$\frac{\text { median }(P 25-P 75)}{1.25(0.64-2.42)}$} & \multirow[t]{2}{*}{$P$} & \multirow{2}{*}{$\frac{\text { median }(P 25-P 75)}{0.32(0.14-0.99)}$} & \multirow[t]{2}{*}{$P$} & \multirow{2}{*}{$\frac{\text { median }(P 25-P 75)}{0.29(0.12-0.70)}$} & \multirow[t]{2}{*}{$P$} \\
\hline all & & & & & & & & \\
\hline \multirow[t]{2}{*}{ age } & $6-11$ years & 409 & $1.34(0.70-2.72)$ & 0.051 & $0.27(0.14-0.85)$ & 0.009 & $0.27(0.12-0.64)$ & 0.18 \\
\hline & $12-19$ years & 459 & $1.14(0.60-2.30)$ & & $0.37(0.14-1.10)$ & & $0.30(0.13-0.77)$ & \\
\hline \multirow[t]{2}{*}{ gender } & male & 429 & $1.22(0.66-2.38)$ & 0.97 & $0.30(0.14-1.03)$ & 0.83 & $0.28(0.12-0.63)$ & 0.21 \\
\hline & female & 439 & $1.27(0.64-2.49)$ & & $0.33(0.14-0.97)$ & & $0.30(0.13-0.78)$ & \\
\hline \multirow[t]{4}{*}{ race/ethnicity ${ }^{b}$} & non-Hispanic white & 229 & $1.23(0.61-2.14)$ & 0.18 & $0.40(0.14-1.23)$ & 0.007 & $0.24(0.11-0.60)$ & 0.02 \\
\hline & Hispanic & 286 & $1.13(0.63-2.33)$ & & $0.24(0.14-0.64)$ & & $0.39(0.15-0.99)$ & \\
\hline & non-Hispanic black & 223 & $1.84(0.98-3.22)$ & & $0.36(0.14-0.95)$ & & $0.36(0.17-0.75)$ & \\
\hline & other & 130 & $1.09(0.61-2.32)$ & & $0.17(0.14-0.93)$ & & $0.29(0.13-0.71)$ & \\
\hline \multirow[t]{4}{*}{ family IPR ${ }^{c}$} & $\leq 1.30$ & 406 & $1.32(0.76-2.55)$ & 0.76 & $0.25(0.14-0.79)$ & 0.03 & $0.30(0.11-0.70)$ & 0.45 \\
\hline & $1.31-3.50$ & 236 & $1.36(0.69-2.53)$ & & $0.34(0.14-1.22)$ & & $0.27(0.13-0.74)$ & \\
\hline & $>3.50$ & 154 & $1.09(0.58-2.16)$ & & $0.39(0.14-1.10)$ & & $0.27(0.12-0.58)$ & \\
\hline & missing & 72 & $1.00(0.47-1.55)$ & & $0.25(0.14-0.74)$ & & $0.45(0.19-1.05)$ & \\
\hline
\end{tabular}

${ }^{a}$ All variables were adjusted using population weights for the sample in which BPA concentration was measured except $N$ (unweighted sample size). ANOVA was used to compare differences of urinary concentrations of BPA, BPF, and BPS among various categorical variables. The analysis of creatinine-adjusted concentrations of BPA, BPS, and BPF is presented in Table S4, Supporting Information. ${ }^{b}$ Race/ethnicity was categorized based on self-reported data into Hispanic (including Mexican and non-Mexican Hispanic), non-Hispanic white, non-Hispanic black, and other race/ ethnicity. ${ }^{37}{ }^{c}$ Family IPRs were categorized as $\leq 1.30,1.31-3.50$, and $>3.50 .{ }^{37,50}$

differences were frequently not statistically significant. $^{26,56,58,61-63}$ Only limited information about gender differences in urinary BPF and BPS levels is available. A biomonitoring study in several Asian countries versus the U.S. observed higher geometric mean levels of BPS in men versus women $(0.239 \mu \mathrm{g} / \mathrm{L}$ vs $0.126 \mu \mathrm{g} / \mathrm{L}$, respectively); however, this difference did not reach statistical significance in the entire study population. ${ }^{30}$

It is noteworthy that men have slightly higher estimated daily intakes of BPA than women based on an analysis of the NHANES 2005-2006 data. ${ }^{17}$ It is currently unknown if there are gender differences in the daily intake of BPF and BPS. In addition to differences in exposures, gender differences in the toxicokinetics of the bisphenols investigated could contribute to gender differences in urinary levels of bisphenols. For example, gender differences in the hepatic expression of UGTs, including the major BPA metabolizing isoform UGB2B15, and other human drug-metabolizing enzymes are well established. ${ }^{64}$ Indeed, gender differences in BPA metabolism have been reported for BPA in a small number of Korean adults, with higher urinary levels of the BPA glucuronide in males, but higher levels of the BPA sulfate in females. ${ }^{65}$ However, these differences in specific BPA conjugates did not translate into significant differences in urinary BPA levels by gender in the Korean study population.

Statistically significant race/ethnicity-dependent differences were observed for BPA $(P=0.007)$ only in the analysis of variance (ANOVA) (Tables 1 vs 2 ). An earlier analysis of data from NHANES 2003-2004 revealed significant differences by race/ethnicity, with lower least-squares geometric mean levels observed in Mexican Americans than non-Hispanic whites and non-Hispanic blacks. ${ }^{26}$ The earlier finding that levels of BPA are lower in Mexican Americans in the NHANES 2003-2004 population is consistent with results from a German biomonitoring study reporting lower levels in children from families with a migration background. ${ }^{66}$ Significant race/ ethnicity-dependent differences in urinary levels were also observed for BPS ( $P=0.001$, Table 1$)$. These findings were confirmed in the linear regression analysis, where urinary levels of BPS in Hispanics ( $\beta$ coefficient $0.23, P=0.02$ ) and non-
Hispanic blacks $(\beta$ coefficient $0.35, P=0.005)$ were significantly different compared to non-Hispanic white (Table 2). A small biomonitoring study investigated an association between race/ethnicity and urinary BPS levels in a small population of mostly Caucasians and Asians from Albany, New York. $^{30}$ This study found higher levels of BPS in Caucasians versus Asians; however, this difference did not reach statistical significance. A recent study reported lower BPS levels in pregnant women of non-European descent living in the Netherlands compared to Dutch women of European descent. $^{32}$

Factors Affecting Urinary Levels of BPA and Its Substitutes in U.S. Adults. In the linear regression analysis (Table 2), the income-to-poverty ratio (IPR) was associated with urinary BPA levels in the adult NHANES 2013-2014 population, with lower BPA levels being detected in individuals from the high versus low IPR group $(\beta$ coefficient -0.14 and $P$ $=0.01)$. Levels of BPF were also significantly different between the medium versus low IPR group ( $\beta$ coefficient 0.30 and $P=$ 0.02). Interestingly, levels of BPF appeared to be higher in the group with a medium family income compared to that with a low family income. Similar to our findings, an earlier analysis of NHANES 2003-2004 data revealed an association between family income and urinary BPA levels. ${ }^{26}$ Income was also significantly associated with urinary BPA levels in Korea, with the lowest levels observed in the highest income group, ${ }^{67}$ whereas no associations were observed in an earlier study of Korean adults. ${ }^{60}$ A biomonitoring study in Germany found no correlation between the socioeconomic status, which includes household income, and BPA exposure levels. ${ }^{66}$ Similarly, urinary BPA levels were not significantly associated with income in the 2007-2009 Canadian Health Measures Survey; however, the least-squares geometric mean BPA level of the third quartile income group was significantly higher compared to that of the fourth quartile income group. ${ }^{56}$ These limited studies suggest that, at the time of each study, household income is linked to region- or country-specific factors that affect exposure to specific bisphenols. For example, the findings from our analysis of the NHANES 2013-2014 data raise the question if differences in BPA versus BPF exposures by 
Table 4. Association of Demographic Factors in Children $(N=868)$ from NHANES 2013-2014 with Urinary BPA, BPF, and BPS Concentrations ${ }^{a}$

\begin{tabular}{|c|c|c|c|c|c|c|c|}
\hline & & \multicolumn{2}{|c|}{ BPA } & \multicolumn{2}{|c|}{$\mathrm{BPF}$} & \multicolumn{2}{|c|}{ BPS } \\
\hline \multicolumn{2}{|c|}{ variable } & $\beta$ coefficient & $P$ & $\beta$ coefficient & $P$ & $\beta$ coefficient & $P$ \\
\hline \multirow[t]{2}{*}{ age } & $6-11$ & {$[\mathrm{ref}]$} & & {$[\mathrm{ref}]$} & & {$[\mathrm{ref}]$} & \\
\hline & $12-19$ & -0.40 & $<0.0001$ & 0.06 & 0.56 & -0.16 & 0.055 \\
\hline \multirow[t]{2}{*}{ gender } & male & {$[\mathrm{ref}]$} & & {$[\mathrm{ref}]$} & & {$[\mathrm{ref}]$} & \\
\hline & female & 0.07 & 0.24 & 0.11 & 0.50 & 0.16 & 0.045 \\
\hline \multirow[t]{4}{*}{ race/ethnicity ${ }^{b}$} & non-Hispanic white & {$[\mathrm{ref}]$} & & {$[\mathrm{ref}]$} & & {$[\mathrm{ref}]$} & \\
\hline & Hispanic & -0.023 & 0.75 & -0.39 & 0.001 & 0.35 & 0.03 \\
\hline & non-Hispanic black & 0.16 & 0.18 & -0.16 & 0.40 & 0.17 & 0.29 \\
\hline & other & -0.008 & 0.95 & -0.28 & 0.13 & 0.14 & 0.19 \\
\hline \multirow[t]{4}{*}{ family $\mathrm{IPR}^{c}$} & $\leq 1.30$ & {$[\mathrm{ref}]$} & & {$[\mathrm{ref}]$} & & {$[\mathrm{ref}]$} & \\
\hline & $1.31-3.50$ & -0.13 & 0.13 & 0.07 & 0.55 & 0.04 & 0.77 \\
\hline & $>3.50$ & -0.27 & 0.053 & 0.08 & 0.53 & -0.09 & 0.42 \\
\hline & missing & -0.43 & 0.002 & -0.26 & 0.13 & 0.38 & 0.01 \\
\hline
\end{tabular}

${ }^{a}$ The analysis of creatinine-adjusted concentrations of BPA, BPS, and BPF is presented in Table S5, Supporting Information. ${ }^{b}$ Race/ethnicity was categorized based on self-reported data into Hispanic (including Mexican and non-Mexican Hispanic), non-Hispanic white, non-Hispanic black, and other race/ethnicity. ${ }^{37}{ }^{c}$ Family IPRs were categorized as $\leq 1.30,1.31-3.50$, and $>3.50$. $^{37,50}$

household income reflect a shift from using BPA to BPA-free (but BPF-containing) consumer products in more affluent U.S. households.

Linear regression analysis revealed that urinary levels of BPA ( $\beta$ coefficient 0.19 and $P=0.01$ ) were higher in current smokers compared with adults who never smoked (Table 2). Higher urinary BPA levels have also been observed in Chinese smokers. ${ }^{62}$ Similarly, women who smoked during pregnancy had higher environmental bisphenol levels in urine in a biomonitoring study from the Netherlands. ${ }^{32}$ Smoking was not associated with BPA levels in the NHANES 2003-2004 data ${ }^{26}$ and in Korean adults. ${ }^{60,67,68} \mathrm{~A}$ negative association between smoking and BPA levels has been reported for the NHANES 2005-2006 population. ${ }^{17}$ Although smoking affects the expression of drug-processing genes in the intestine and the liver, these changes are expected to increase the expression of drug-processing genes involved in the metabolism of BPA and its substitutes and, consequently, do not explain higher BPA levels in smokers. It is more likely that smoking is a surrogate for other factors associated with exposure to bisphenols. ${ }^{17}$

Statistically significant differences based on alcohol intake were observed for BPS in ANOVA $(P=0.03$, Table 1). Moreover, in the linear regression analysis, alcohol intake was associated with urinary BPS levels, with alcohol intake being significantly different between the moderate drinker and nondrinker groups ( $\beta$ coefficient -0.29 and $P=0.004$, Table 2$)$. In addition, physical activity was associated with urinary BPA levels $(\beta$ coefficient 0.14 and $P=0.02$, Table 2$)$ in the linear regression analysis. It is currently unclear why these lifestyle factors are associated with urinary levels of specific bisphenols. As for smoking, these factors may be surrogates for physiological or lifestyle factors affecting exposures to bisphenols and further studies are needed to better characterize these factors.

Urinary Concentrations of BPA and Its Substitutes in U.S. Children and Adolescents. Median bisphenol concentrations in U.S. children (6-11 years old) were $1.34 \mu \mathrm{g} / \mathrm{L}$ $(0.70-2.72 \mu \mathrm{g} / \mathrm{L} ; N=409)$ for BPA, $0.27 \mu \mathrm{g} / \mathrm{L}(0.14-0.85$ $\mu \mathrm{g} / \mathrm{L})$ for $\mathrm{BPF}$, and $0.27 \mu \mathrm{g} / \mathrm{L}(0.12-0.64 \mu \mathrm{g} / \mathrm{L})$ for BPS (Table 3). For comparison, creatinine-adjusted median urinary levels of BPA and its substitutes in children were $1.80 \mu \mathrm{g} / \mathrm{g}$ creatinine (1.05-3.08 $\mu \mathrm{g} / \mathrm{g}$ creatinine) for BPA, $0.45 \mu \mathrm{g} / \mathrm{g}$ creatinine $(0.19-1.18 \mu \mathrm{g} / \mathrm{g}$ creatinine) for BPF, and $0.40 \mu \mathrm{g} / \mathrm{g}$ creatinine $(0.21-0.78 \mu \mathrm{g} / \mathrm{g}$ creatinine) for BPS (Table S4). Adolescents (12-19 years) in the NHANES 2013-2014 population $(N=459)$ had urinary levels of $1.14 \mu \mathrm{g} / \mathrm{L}(0.60-$ $2.30 \mu \mathrm{g} / \mathrm{L})$ for BPA, $0.37 \mu \mathrm{g} / \mathrm{L}(0.14-1.10 \mu \mathrm{g} / \mathrm{L})$ for BPF, and $0.30 \mu \mathrm{g} / \mathrm{L}(0.13-0.77 \mu \mathrm{g} / \mathrm{L})$ for BPS (Table 3$)$. In this age group, creatinine-adjusted levels were $0.93 \mu \mathrm{g} / \mathrm{g}$ creatinine $(0.60-1.71 \mu \mathrm{g} / \mathrm{g}$ creatinine), $0.38 \mu \mathrm{g} / \mathrm{g}$ creatinine $(0.15-1.04$ $\mu \mathrm{g} / \mathrm{g}$ creatinine), and $0.29(0.16-0.58 \mu \mathrm{g} / \mathrm{g}$ creatinine $)$ for BPA, BPF, and BPS, respectively (Table S4).

Children had higher median BPA levels compared to adolescents $(P=0.051$; Table 3$)$, a difference that reached statistical significance in the linear regression analysis $(\beta$ coefficient -0.40 and $P<0.0001$; Table 4$)$. The opposite trend was observed for urinary BPF levels in children; however, this difference was not statistically significant in the linear regression analysis. Urinary BPS levels were not significantly different between both age groups. An earlier analysis of the NHANES 2003-2004 data revealed a decrease in urinary levels of BPA from children to adolescents to adults. ${ }^{26}$ Human biomonitoring studies from different parts of the world consistently report higher urinary levels of BPA in children than in adults. ${ }^{58,63,67,69}$ BPS levels were also higher in adolescents than in adults in a study of human exposures to BPS in Asia and the U.S. ${ }^{30}$ These earlier findings are consistent with a higher xenobiotic intake of children and adolescents compared to adults due to a higher food intake and respiratory rate compared to adults; exposure to bisphenols via ingestion of household dust; more (dermal) contact with products containing BPA or its substitutes; and differences in the absorption, distribution, metabolism, and excretion of xenobiotics between children and adults. It is important to note that urinary levels of BPA were significantly higher in children compared to adults in the NHANES 20032004 population, ${ }^{26}$ whereas median urinary levels of BPA in young adults (20-39 years old) were higher compared to those in children (6-11 years old) in the NHANES 2013-2014 population (1.47 vs $1.34 \mu \mathrm{g} / \mathrm{L}$ ), possibly because of the ban of BPA in certain consumer products in the United States and other countries.

In the linear regression analysis, gender was associated with BPS levels, but not with BPA and BPF levels, in children ( $\beta$ coefficient $0.16, P=0.045$; Table 4$)$. BPS levels were higher in 
female children compared to male children. Significant differences based on race/ethnicity were observed for urinary BPF $(P=0.007)$ and BPS $(P=0.02)$ (Table 3$)$. In the linear regression analysis (Table 4 ), BPF levels were significantly lower in Hispanic children compared to non-Hispanic whites ( $\beta$ coefficient $-0.39, P=0.001$ ). The opposite trend was observed for BPS levels, with higher urinary BPS levels being observed in Hispanic compared to non-Hispanic white children ( $\beta$ coefficient $0.35, P=0.03)$. Urinary levels of BPF $(P=0.03)$ in children were associated with family income in ANOVA (Table 3). As for the adult NHANES 2013-2014 population (Table 2), linear regression showed a negative association between BPA levels in children and family incomes, whereby children from the high-family income group had a lower urinary level of BPA compared to those from the low-family income group ( $\beta$ coefficient $-0.27, P=0.053$; Table 4 ). These results demonstrate that complex social, economic, and environmental factors modulate the exposure of children and adolescents to bisphenols.

Human Health Implications. Bisphenols are ubiquitous environmental pollutants, ${ }^{9}$ and as indicated by the high detection frequencies in this study, both U.S. adults and children are continuously exposed to these environmental pollutants. Exposure patters for BPA across age groups have changed over time, with children and adolescents having lower exposures relative to adults in NHANES 2013-2014, suggesting that the replacement of BPA, especially in food contact materials, has resulted in a reduction of human exposures to BPA. However, exposures to other bisphenols, in particular BPS, are growing human health concerns not only because of the high detection frequency but also because of emerging evidence that BPS, but not BPF, exposures increase in the U.S. population. ${ }^{28}$ It is important to note that the associations between demographic and lifestyle factors and urinary levels of bisphenols observed in this analysis of the NHANES 2013-2014 data are complex and cannot be easily explained by the same routes of exposure; that is, findings for BPA cannot be simply applied to other bisphenols. Because of the ubiquitous exposure of the U.S. population to BPA, BPF, and BPS, more research is therefore needed to characterize the routes of exposure in different segments of the U.S. population and, ultimately, identify modifiable factors to reduce human exposures to specific bisphenols.

\section{EXPERIMENTAL SECTION}

NHANES Overview. NHANES is a nationally representative survey of the noninstitutionalized civilian resident population of the United States. ${ }^{45}$ NHANES data are released by the Centers for Disease Control and Prevention in 2 year cycles. Participants are selected using census data based on their age, gender, and racial/ethnic background through a multistage probability sampling design. NHANES collects extensive data through questionnaires and physical examinations to assess the health and nutritional status of the general U.S. population. Moreover, human biospecimens, such as blood and urine samples, are collected for laboratory tests during each cycle, including the measurements of environmental pollutants. NHANES is reviewed and approved by the National Center for Health Statistics Institutional Review Board, and written informed consent is obtained from all participants. A detailed description of NHANES is available elsewhere. ${ }^{46}$

For this study, we analyzed data from the NHANES 20132014 cycle (see Table S1 for the sources of the data). BPS and
BPF exposure of the U.S. population was evaluated for the first time in this cycle, although BPA exposure has been assessed in earlier cycles. ${ }^{26}$ The participants of NHANES 2013-2014 $(n=$ 10175 ) included 4406 children and 5769 adults. A one-third subsample of participants aged 6 years or older was randomly selected for the measurements of BPA, BPS, and BPF in spot urine samples. Ultimately, 2676 participants were included in our analysis of the NHANES 2013-2014 data after excluding those with missing data on urinary BPA, BPS, or BPF concentrations.

Analysis of Total Urinary Levels of BPA, BPF, and BPS. Total urinary levels of BPA, BPF, and BPS were measured at the Division of Laboratory Sciences, National Center for Environmental Health, Centers for Disease Control and Prevention, using published procedures. Briefly, the total concentration (free and conjugated) of the target analytes in urine samples was measured after deconjugation at $37^{\circ} \mathrm{C}$ for 4 $\mathrm{h}$ with $\beta$-glucuronidase/sulfatase ( $4 \mathrm{mg} / \mathrm{mL} ; 463000 \mathrm{U} / \mathrm{g}$ solid in $1 \mathrm{M}$ ammonium acetate buffer at $\mathrm{pH}$ 5; Sigma-Aldrich Laboratories, St. Louis, MO, USA). The extent of the deconjugation reaction was assessed by adding a deconjugation standard solution containing 4-methylumbelliferyl glucuronide, 4-methylumbelliferyl sulfate, and ${ }^{13} \mathrm{C}_{4}$-4-methylumbelliferone $(500 \mathrm{ng} / \mathrm{mL}$ each; Cambridge Isotope Laboratories, Tewksbury, MA, USA) to all incubation mixtures and monitoring the 4-methylumbelliferone $/{ }^{13} \mathrm{C}_{4}$-4-methylumbelliferone peak area ratio after sample incubation as reported previously. ${ }^{47-49}$ An area count ratio $>0.4$ was considered acceptable for the deconjugation reaction of unknown samples. ${ }^{49}$ Total BPA, BPF, and BPS were quantified after deconjugation by on-line solidphase extraction (SPE)-high-performance liquid chromatography (HPLC) with atmospheric pressure chemical ionization (APCI)-mass spectrometry (MS)/MS in the negative-ion APCI mode. Details of the on-line SPE-HPLC-MS/MS system and the instrument parameters have been reported previously. ${ }^{47,48}$ The LODs were $0.2 \mu \mathrm{g} / \mathrm{L}$ for BPA, $0.2 \mu \mathrm{g} / \mathrm{L}$ for $\mathrm{BPF}$, and $0.1 \mu \mathrm{g} / \mathrm{L}$ for BPS. For analytes with levels below the LOD, an imputed fill value was assigned as the LOD divided by the square root of 2 . All analyses were accompanied by quality assurance/quality control samples to account for any possible background contamination of the sampling materials with bisphenols. ${ }^{49}$ Specifically, the calculated concentrations of the target analytes in the reagent blanks were less than three times the LOD. Moreover, all standards, blanks, and unknown samples were prepared following the same procedure; thus, the background, represented as the intercept of the calibration curve, was automatically subtracted during the quantification of all analytes. In addition to the reagent blanks, two empty vials were also included with each batch to check for potential background contamination.

Demographic and Lifestyle Factors. Information on demographic (i.e., age, gender, race/ethnicity, education, and family income) and lifestyle factors (i.e., physical activity, smoking status, and alcohol intake) of study participants was collected using standardized questionnaires. Race/ethnicity was categorized based on self-reported data into Hispanic (including Mexican and non-Mexican Hispanic), non-Hispanic white, non-Hispanic black, and other race/ethnicity. ${ }^{37}$ Family IPRs were categorized as $\leq 1.30,1.31-3.50$, and $>3.50$ based on the cutoff points of the Supplemental Nutrition Assistance Program. ${ }^{37,50}$ In accordance with the NHANES Analytic Guidelines, ${ }^{70}$ individuals who smoked less than 100 cigarettes in their lifetime were defined as never smokers; those who 
Table 5. Subject Demographics and Characteristics $(N=2676)^{a}$

\begin{tabular}{|c|c|c|c|c|c|c|}
\hline \multirow{2}{*}{\multicolumn{2}{|c|}{ characteristics }} & \multicolumn{5}{|c|}{ age, years } \\
\hline & & \multirow{2}{*}{$\frac{6-11}{409}$} & \multirow{2}{*}{$\frac{12-19}{459}$} & \multirow{2}{*}{$\frac{20-39}{598}$} & \multirow{2}{*}{$\frac{40-59}{607}$} & \multirow{2}{*}{$\begin{array}{l}\quad \geq 60 \\
603\end{array}$} \\
\hline number of participants & & & & & & \\
\hline \multirow[t]{2}{*}{ gender, \% (SE) } & male & $50.11(3.80)$ & $51.00(2.37)$ & $49.63(2.58)$ & $49.30(2.73)$ & $45.81(2.84)$ \\
\hline & female & $49.88(3.80)$ & $49.00(2.37)$ & $50.37(2.58)$ & $50.70(2.73)$ & $54.19(2.84)$ \\
\hline \multirow[t]{4}{*}{ race/ethnicity, ${ }^{b} \%$ (SE) } & non-Hispanic white & $51.12(5.53)$ & $54.11(4.70)$ & $56.67(4.47)$ & $65.83(3.40)$ & $77.61(3.50)$ \\
\hline & Hispanic & $24.31(3.93)$ & $22.23(3.95)$ & $20.61(3.06)$ & $14.15(2.61)$ & $7.88(1.94)$ \\
\hline & non-Hispanic black & $13.59(2.32)$ & $14.92(2.21)$ & $12.83(2.16)$ & $11.60(1.75)$ & $8.97(1.92)$ \\
\hline & other & $10.98(2.25)$ & $8.73(1.50)$ & $9.90(1.55)$ & $8.42(1.25)$ & $5.55(1.07)$ \\
\hline \multirow[t]{4}{*}{ family $\mathrm{IPR},{ }^{c} \%$ (SE) } & $\leq 1.30$ & $38.03(4.53)$ & $32.57(3.64)$ & $31.03(2.74)$ & $20.34(3.93)$ & $17.12(1.87)$ \\
\hline & $1.31-3.50$ & $30.18(2.32)$ & $31.92(3.56)$ & $34.23(2.64)$ & $28.35(2.64)$ & $35.32(2.47)$ \\
\hline & $>3.50$ & $25.38(5.09)$ & $28.19(2.77)$ & $27.12(2.54)$ & $43.38(3.97)$ & $39.77(3.03)$ \\
\hline & missing & $6.41(1.64)$ & $7.32(1.67)$ & $7.62(1.59)$ & $7.93(1.35)$ & $7.79(1.55)$ \\
\hline
\end{tabular}

${ }^{a}$ All variables were adjusted using population weights for the sample in which BPA concentrations were measured except the number of participants (SE, standard error). All estimates were weighted. ${ }^{b}$ Race/ethnicity was categorized based on self-reported data into Hispanic (including Mexican and non-Mexican Hispanic), non-Hispanic white, non-Hispanic black, and other race/ethnicity. ${ }^{37}{ }^{c}$ Family IPRs were categorized as $\leq 1.30$, 1.31-3.50, and $>3.50 .37,50$

smoked more than 100 cigarettes but do not smoke currently were considered ever smokers; and those who currently smoke cigarettes were classified as current smokers. Alcohol intake was categorized as $0,0.1-28$, and $\geq 28 \mathrm{~g} /$ day for men and $0,0.1-$ 14 , and $\geq 14 \mathrm{~g} /$ day for women. ${ }^{51}$ Self-reported physical activity was used to derive metabolic equivalent of task (MET) minutes per week and categorized as $<600,600-1200$, and $>1200$ MET min/week. ${ }^{37}$ A summary of the characteristics of the study participants is provided in Table 5 .

Statistical Analyses. The NHANES uses a complex, multistage probability sampling design to represent the civilian, noninstitutionalized U.S. population. Therefore, appropriate published sample weights were applied to account for the differential probability of selection, nonresponse adjustment, and adjustment to independent population controls. The Taylor series linearization method was used for variance estimation to account for stratification and clustering, following the NHANES Analytic Guidelines. ${ }^{70}$

We used ANOVA to compare differences of urinary concentrations of BPA, BPF, and BPS (log transformed) among various categorical variables. We conducted linear regression analyses by including all variables simultaneously in the model to detect independent effects of each variable. Urinary creatinine levels were adjusted in the model as previously recommended to account for urine dilution. ${ }^{52}$ To facilitate a comparison with other studies, we also report analogous analyses of urinary bisphenol levels adjusted for creatinine in the Supporting Information (Tables S2 to S5). All statistical analyses were performed with SAS software (version 9.4; SAS Institute). $P<0.05$ was considered statistically significant.

\section{ASSOCIATED CONTENT}

\section{S Supporting Information}

The Supporting Information is available free of charge on the ACS Publications website at DOI: 10.1021/acsomega.8b00824.

File names and URLs of the original data and analyses of associations of creatinine-adjusted urinary levels of BPA, $\mathrm{BPF}$, and BPS with various demographic factors in the NHANES 2013-2014 population (PDF)

\section{AUTHOR INFORMATION}

\section{Corresponding Author}

*E-mail: wei-bao@uiowa.edu. Phone: 319-384-1546. Fax: 319384-4155 (W.B.).

ORCID $\odot$

Hans-Joachim Lehmler: 0000-0001-9163-927X

Wei Bao: 0000-0002-7301-5786

\section{Notes}

The authors declare no competing financial interest.

\section{ACKNOWLEDGMENTS}

This study was supported by the National Institute of Environmental Health Sciences/National Institutes of Health [P30 ES005605]. The findings and conclusions in this manuscript are those of the authors and do not necessarily represent the views of the National Institute of Environmental Health Sciences/National Institutes of Health.

\section{REFERENCES}

(1) PR Newswire. 2016. Bisphenol-A-A Global Market Overview. Available http://www.prnewswire.com/news-releases/bisphenol-a-aglobal-market-overview-300282092.html (accessed May 4, 2018).

(2) Milner, L. Chemical Profiles; ICIS Chemical Business, 2017; p 1.

(3) Tsai, W. T. Human health risk on environmental exposure to Bisphenol-A: a review. J. Environ. Sci. Health, Part C: Environ. Carcinog. Ecotoxicol. Rev. 2006, 24, 225-255.

(4) FDA (Food and Drug Administration). 2014. Bisphenol A (BPA): Use in food contact application. Available https://www.fda. gov/newsevents/publichealthfocus/ucm064437.htm (accessed May 4, 2018).

(5) European Commission. 2011. Bisphenol A: EU ban on baby bottles to enter into force tomorrow. Available http://europa.eu/ rapid/press-release IP-11-664 en.htm (accessed May 4, 2018).

(6) Government of Canada. 2016. Bisphenol A (BPA). Available https://www.canada.ca/en/health-canada/services/home-gardensafety/bisphenol-bpa.html (accessed May 4, 2018).

(7) Hormann, A. M.; Vom Saal, F. S.; Nagel, S. C.; Stahlhut, R. W.; Moyer, C. L.; Ellersieck, M. R.; Welshons, W. V.; Toutain, P.-L.; Taylor, J. A. Holding thermal receipt paper and eating food after using hand sanitizer results in high serum bioactive and urine total levels of bisphenol A (BPA). PLoS One 2014, 9, e110509.

(8) European Chemicals Agency. Available https://echa.europa.eu/ information-on-chemicals/registered-substances (accessed May 4, 2018). 
(9) Chen, D.; Kannan, K.; Tan, H.; Zheng, Z.; Feng, Y.-L.; Wu, Y.; Widelka, M. Bisphenol analogues other than BPA: Environmental occurrence, human exposure, and toxicity-a review. Environ. Sci. Technol. 2016, 50, 5438-5453.

(10) Cousins, I. T.; Staples, C. A.; Kleĉka, G. M.; Mackay, D. A multimedia assessment of the environmental fate of bisphenol A. Hum. Ecol. Risk Assess. 2002, 8, 1107-1135.

(11) Liao, C.; Kannan, K. Concentrations and profiles of bisphenol A and other bisphenol analogues in foodstuffs from the United States and their implications for human exposure. J. Agric. Food Chem. 2013, $61,4655-4662$.

(12) Zoller, O.; Brüschweiler, B. J.; Magnin, R.; Reinhard, H.; Rhyn, P.; Rupp, H.; Zeltner, S.; Felleisen, R. Natural occurrence of bisphenol F in mustard. Food Addit. Contam., Part A: Chem., Anal., Control, Exposure Risk Assess. 2016, 33, 137-146.

(13) Huang, R.-p.; Liu, Z.-h.; Yuan, S.-f.; Yin, H.; Dang, Z.; Wu, P.-x. Worldwide human daily intakes of bisphenol A (BPA) estimated from global urinary concentration data (2000-2016) and its risk analysis. Environ. Pollut. 2017, 230, 143-152.

(14) Geens, T.; Aerts, D.; Berthot, C.; Bourguignon, J.-P.; Goeyens, L.; Lecomte, P.; Maghuin-Rogister, G.; Pironnet, A.-M.; Pussemier, L.; Scippo, M.-L.; Van Loco, J.; Covaci, A. A review of dietary and nondietary exposure to bisphenol-A. Food Chem. Toxicol. 2012, 50, 37253740.

(15) Wang, W.; Abualnaja, K. O.; Asimakopoulos, A. G.; Covaci, A.; Gevao, B.; Johnson-Restrepo, B.; Kumosani, T. A.; Malarvannan, G.; Minh, T. B.; Moon, H.-B.; Nakata, H.; Sinha, R. K.; Kannan, K. A comparative assessment of human exposure to tetrabromobisphenol $\mathrm{A}$ and eight bisphenols including bisphenol A via indoor dust ingestion in twelve countries. Environ. Int. 2015, 83, 183-191.

(16) Liao, C.; Kannan, K. A survey of alkylphenols, bisphenols, and triclosan in personal care products from China and the United States. Arch. Environ. Contam. Toxicol. 2014, 67, 50-59.

(17) Lakind, J. S.; Naiman, D. Q. Daily intake of bisphenol A and potential sources of exposure: 2005-2006 National Health and Nutrition Examination Survey. J. Exposure Sci. Environ. Epidemiol. 2011, 21, 272-279.

(18) Dekant, W.; Völkel, W. Human exposure to bisphenol A by biomonitoring: methods, results and assessment of environmental exposures. Toxicol. Appl. Pharmacol. 2008, 228, 114-134.

(19) Thayer, K. A.; Taylor, K. W.; Garantziotis, S.; Schurman, S. H.; Kissling, G. E.; Hunt, D.; Herbert, B.; Church, R.; Jankowich, R.; Churchwell, M. I.; Scheri, R. C.; Birnbaum, L. S.; Bucher, J. R. Bisphenol A, bisphenol S, and 4-hydroxyphenyl 4-isoprooxyphenylsulfone (BPSIP) in urine and blood of cashiers. Environ. Health Perspect. 2016, 124, 437-444.

(20) Hanioka, N.; Naito, T.; Narimatsu, S. Human UDPglucuronosyltransferase isoforms involved in bisphenol A glucuronidation. Chemosphere 2008, 74, 33-36.

(21) Gramec Skledar, D.; Troberg, J.; Lavdas, J.; Peterlin Mašič, L.; Finel, M. Differences in the glucuronidation of bisphenols $F$ and $S$ between two homologous human UGT enzymes, $1 \mathrm{~A} 9$ and $1 \mathrm{~A} 10$. Xenobiotica 2015, 45, 511-519.

(22) Pottenger, L. H.; Domoradzki, J. Y.; Markham, D. A.; Hansen, S. C.; Cagen, S. Z.; Waechter, J. M. The relative bioavailability and metabolism of bisphenol $\mathrm{A}$ in rats is dependent upon the route of administration. Toxicol. Sci. 2000, 54, 3-18.

(23) Völkel, W.; Colnot, T.; Csanády, G. A.; Filser, J. G.; Dekant, W. Metabolism and kinetics of bisphenol A in humans at low doses following oral administration. Chem. Res. Toxicol. 2002, 15, 12811287.

(24) Taylor, J. A.; vom Saal, F. S.; Welshons, W. V.; Drury, B.; Rottinghaus, G.; Hunt, P. A.; Toutain, P.-L.; Laffont, C. M.; VandeVoort, C. A. Similarity of bisphenol A pharmacokinetics in rhesus monkeys and mice: Relevance for human exposure. Environ. Health Perspect. 2011, 119, 422-430.

(25) Koch, H. M.; Kolossa-Gehring, M.; Schröter-Kermani, C.; Angerer, J.; Brüning, T. Bisphenol A in $24 \mathrm{~h}$ urine and plasma samples of the German Environmental Specimen Bank from 1995 to 2009: a retrospective exposure evaluation. J. Exposure Sci. Environ. Epidemiol. 2012, 22, 610-616.

(26) Calafat, A. M.; Ye, X.; Wong, L.-Y.; Reidy, J. A.; Needham, L. L. Exposure of the U.S. population to bisphenol A and 4-tertiaryoctylphenol: 2003-2004. Environ. Health Perspect. 2008, 116, 39-44.

(27) Calafat, A. M.; Kuklenyik, Z.; Reidy, J. A.; Caudill, S. P.; Ekong, J.; Needham, L. L. Urinary concentrations of bisphenol A and 4nonylphenol in a human reference population. Environ. Health Perspect. 2005, 113, 391-395.

(28) Ye, X.; Wong, L.-Y.; Kramer, J.; Zhou, X.; Jia, T.; Calafat, A. M. Urinary concentrations of bisphenol A and three other bisphenols in convenience samples of U.S. adults during 2000-2014. Environ. Sci. Technol. 2015, 49, 11834-11839.

(29) Vandenberg, L. N.; Hauser, R.; Marcus, M.; Olea, N.; Welshons, W. V. Human exposure to bisphenol A (BPA). Reprod. Toxicol. 2007, 24, 139-177.

(30) Liao, C.; Liu, F.; Alomirah, H.; Loi, V. D.; Mohd, M. A.; Moon, H.-B.; Nakata, H.; Kannan, K. Bisphenol S in urine from the United States and seven Asian countries: occurrence and human exposures. Environ. Sci. Technol. 2012, 46, 6860-6866.

(31) Yang, Y.; Guan, J.; Yin, J.; Shao, B.; Li, H. Urinary levels of bisphenol analogues in residents living near a manufacturing plant in south China. Chemosphere 2014, 112, 481-486.

(32) Philips, E. M.; Jaddoe, V. W. V.; Asimakopoulos, A. G.; Kannan, K.; Steegers, E. A. P.; Santos, S.; Trasande, L. Bisphenol and phthalate concentrations and its determinants among pregnant women in a population-based cohort in the Netherlands, 2004-5. Environ. Res. 2018, 161, 562-572.

(33) Deceuninck, Y.; Bichon, E.; Marchand, P.; Boquien, C.-Y.; Legrand, A.; Boscher, C.; Antignac, J. P.; Le Bizec, B. Determination of bisphenol $\mathrm{A}$ and related substitutes/analogues in human breast milk using gas chromatography-tandem mass spectrometry. Anal. Bioanal. Chem. 2015, 407, 2485-2497.

(34) Liu, J.; Li, J.; Wu, Y.; Zhao, Y.; Luo, F.; Li, S.; Yang, L.; Moez, E. K.; Dinu, I.; Martin, J. W. Bisphenol A metabolites and bisphenol S in paired maternal and cord serum. Environ. Sci. Technol. 2017, 51, 24562463.

(35) Richter, C. A.; Birnbaum, L. S.; Farabollini, F.; Newbold, R. R.; Rubin, B. S.; Talsness, C. E.; Vandenbergh, J. G.; Walser-Kuntz, D. R; vom Saal, F. S. In vivo effects of bisphenol $\mathrm{A}$ in laboratory rodent studies. Reprod. Toxicol. 2007, 24, 199-224.

(36) Rochester, J. R. Bisphenol A and human health: a review of the literature. Reprod. Toxicol. 2013, 42, 132-155.

(37) Liu, B.; Lehmler, H.-J.; Sun, Y.; Xu, G.; Liu, Y.; Zong, G.; Sun, Q.; Hu, F. B.; Wallace, R. B.; Bao, W. Bisphenol A substitutes and obesity in US adults: analysis of a population-based, cross-sectional study. Lancet Planet. Health 2017, 1, e114-e122.

(38) Asimakopoulos, A. G.; Xue, J.; DeCarvalho, B. P.; Iyer, A.; Abualnaja, K. O.; Yaghmoor, S. S.; Kumosani, T. A.; Kannan, K. Urinary biomarkers of exposure to 57 xenobiotics and its association with oxidative stress in a population in Jeddah, Saudi Arabia. Environ. Res. 2016, 150, 573-581.

(39) Andrianou, X. D.; Gängler, S.; Piciu, A.; Charisiadis, P.; Zira, C.; Aristidou, K.; Piciu, D.; Hauser, R.; Makris, K. C. Human exposures to bisphenol $\mathrm{A}$, bisphenol $\mathrm{F}$ and chlorinated bisphenol A derivatives and thyroid function. PLoS One 2016, 11, e0155237.

(40) Rochester, J. R.; Bolden, A. L. Bisphenol S and F: A systematic review and comparison of the hormonal activity of bisphenol A substitutes. Environ. Health Perspect. 2015, 123, 643-650.

(41) Rosenmai, A. K.; Dybdahl, M.; Pedersen, M.; Alice van VugtLussenburg, B. M.; Wedebye, E. B.; Taxvig, C.; Vinggaard, A. M. Are structural analogues to bisphenol a safe alternatives? Toxicol. Sci. 2014, 139, 35-47.

(42) Cabaton, N.; Dumont, C.; Severin, I.; Perdu, E.; Zalko, D.; Cherkaoui-Malki, M.; Chagnon, M.-C. Genotoxic and endocrine activities of bis(hydroxyphenyl)methane (bisphenol F) and its derivatives in the HepG2 cell line. Toxicology 2009, 255, 15-24. 
(43) Boucher, J. G.; Ahmed, S.; Atlas, E. Bisphenol S induces adipogenesis in primary human preadipocytes from female donors. Endocrinology 2016, 157, 1397-1407.

(44) Boucher, J. G.; Gagné, R.; Rowan-Carroll, A.; Boudreau, A.; Yauk, C. L.; Atlas, E. Bisphenol A and bisphenol S induce distinct transcriptional profiles in differentiating human primary preadipocytes. PLoS One 2016, 11, e0163318.

(45) Sobus, J. R.; DeWoskin, R. S.; Tan, Y.-M.; Pleil, J. D.; Phillips, M. B.; George, B. J.; Christensen, K.; Schreinemachers, D. M.; Williams, M. A.; Hubal, E. A.; Edwards, S. W. Uses of NHANES biomarker data for chemical risk assessment: Trends, challenges, and opportunities. Environ. Health Perspect. 2015, 123, 919-927.

(46) CDC. National Health and Nutrition Examination Survey. Available at http://www.cdc.gov/nchs/nhanes/about_nhanes.htm (accessed May 4, 2018).

(47) Ye, X.; Kuklenyik, Z.; Needham, L. L.; Calafat, A. M. Automated on-line column-switching HPLC-MS/MS method with peak focusing for the determination of nine environmental phenols in urine. Anal. Chem. 2005, 77, 5407-5413.

(48) Zhou, X.; Kramer, J. P.; Calafat, A. M.; Ye, X. Automated on-line column-switching high performance liquid chromatography isotope dilution tandem mass spectrometry method for the quantification of bisphenol A, bisphenol F, bisphenol S, and 11 other phenols in urine. J. Chromatogr. B: Biomed. Sci. Appl. 2014, 944, 152-156.

(49) CDC. National Health and Nutrition Examination Survey. Laboratory Procedure Manual. Available at https://www.cdc.gov/ nchs/data/nhanes/nhanes_13_14/EPHPP_H_MET.pdf (accessed May 4, 2018).

(50) Johnson, C. L.; Paulose-Ram, R.; Ogden, C. L.; Carroll, M. D.; Kruszon-Moran, D.; Dohrmann, S. M.; Curtin, L. R. National Health and Nutrition Examination Survey: Analytic Guidelines, 1999-2010. Vital Health Stat. 2 2013, 161, 1-24.

(51) Office of Disease Prevention and Health Promotion (ODPHP). Dietary Guidelines 2015-2020. Appendix 9. Alcohol. Available at https://health.gov/dietaryguidelines/2015/guidelines/appendix-9/ (accessed May 4, 2018).

(52) Barr, D. B.; Wilder, L. C.; Caudill, S. P.; Gonzalez, A. J.; Needham, L. L.; Pirkle, J. L. Urinary creatinine concentrations in the U.S. population: implications for urinary biologic monitoring measurements. Environ. Health Perspect. 2005, 113, 192-200.

(53) Street, C. M.; Zhu, Z.; Finel, M.; Court, M. H. Bisphenol-A glucuronidation in human liver and breast: identification of UDPglucuronosyltransferases (UGTs) and influence of genetic polymorphisms. Xenobiotica 2017, 47, 1-10.

(54) Green Century Capital Management. Seeking Safer Packaging: Ranking Packaged Food Companies on BPA, 2010. Available http:// greencentury.staging.wpengine.com/wp-content/uploads/2013/05/ bpareport2010.pdf (accessed May 4, 2018).

(55) Konkel, L. Thermal reaction: The spread of bisphenol $S$ via paper products. Environ. Health Perspect. 2013, 121, a76.

(56) Bushnik, T.; Haines, D.; Levallois, P.; Levesque, J.; Van Oostdam, J.; Viau, C. Lead and bisphenol A concentrations in the Canadian population. Health Rep. 2010, 21, 7-18.

(57) Myridakis, A.; Chalkiadaki, G.; Fotou, M.; Kogevinas, M.; Chatzi, L.; Stephanou, E. G. Exposure of preschool-age Greek children (RHEA cohort) to bisphenol A, parabens, phthalates, and organophosphates. Environ. Sci. Technol. 2016, 50, 932-941.

(58) Zhang, Z.; Alomirah, H.; Cho, H.-S.; Li, Y.-F.; Liao, C.; Minh, T. B.; Mohd, M. A.; Nakata, H.; Ren, N.; Kannan, K. Urinary bisphenol A concentrations and their implications for human exposure in several asian countries. Environ. Sci. Technol. 2011, 45, 7044-7050.

(59) Zhang, T.; Xue, J.; Gao, C.-z.; Qiu, R.-1.; Li, Y.-X.; Li, X.; Huang, M.-zZ.; Kannan, K. Urinary concentrations of bisphenols and their association with biomarkers of oxidative stress in people living near ewaste recycling facilities in China. Environ. Sci. Technol. 2016, 50, $4045-4053$.

(60) Kim, K.; Park, H.; Yang, W.; Lee, J. H. Urinary concentrations of bisphenol $\mathrm{A}$ and triclosan and associations with demographic factors in the Korean population. Environ. Res. 2011, 111, 1280-1285.
(61) Mahalingaiah, S.; Meeker, J. D.; Pearson, K. R.; Calafat, A. M.; Ye, X.; Petrozza, J.; Hauser, R. Temporal variability and predictors of urinary bisphenol a concentrations in men and women. Environ. Health Perspect. 2008, 116, 173-178.

(62) He, Y.; Miao, M.; Herrinton, L. J.; Wu, C.; Yuan, W.; Zhou, Z.; $\mathrm{Li}$, D.-K. Bisphenol A levels in blood and urine in a Chinese population and the personal factors affecting the levels. Environ. Res. 2009, 109, 629-633.

(63) Heffernan, A. L.; Aylward, L. L.; Toms, L. M. L.; Eaglesham, G.; Hobson, P.; Sly, P. D.; Mueller, J. F. Age-related trends in urinary excretion of bisphenol $\mathrm{A}$ in Australian children and adults: evidence from a pooled sample study using samples of convenience. J. Toxicol. Environ. Health, Part A 2013, 76, 1039-1055.

(64) Waxman, D. J.; Holloway, M. G. Sex differences in the expression of hepatic drug metabolizing enzymes. Mol. Pharmacol. 2009, 76, 215-228.

(65) Kim, Y.-H.; Kim, C.-S.; Park, S.; Han, S. Y.; Pyo, M.-Y.; Yang, M. Gender differences in the levels of bisphenol A metabolites in urine. Biochem. Biophys. Res. Commun. 2003, 312, 441-448.

(66) Becker, K.; Güen, T.; Seiwert, M.; Conrad, A.; Pick-Fuß, H.; Müller, J.; Wittassek, M.; Schulz, C.; Kolossa-Gehring, M. GerES IV: Phthalate metabolites and bisphenol A in urine of German children. Int. J. Hyg. Environ. Health 2009, 212, 685-692.

(67) Park, J.-H.; Hwang, M.-S.; Ko, A.; Jeong, D.-H.; Lee, J.-M.; Moon, G.; Lee, K.-S.; Kho, Y.-H.; Shin, M.-K.; Lee, H.-S.; Kang, H.-S.; Suh, J.-H.; Hwang, I.-G. Risk assessment based on urinary bisphenol A levels in the general Korean population. Environ. Res. 2016, 150, 606615.

(68) Yang, M.; Kim, S.-Y.; Chang, S.-S.; Lee, I.-S.; Kawamoto, T. Urinary concentrations of bisphenol A in relation to biomarkers of sensitivity and effect and endocrine-related health effects. Environ. Mol. Mutagen. 2006, 47, 571-578.

(69) Battal, D.; Cok, I.; Unlusayin, I.; Aktas, A.; Tunctan, B. Determination of urinary levels of Bisphenol A in a Turkish population. Environ. Monit. Assess. 2014, 186, 8443-8452.

(70) CDC. National Health and Nutrition Examination Survey: Analytic Guidelines. Available at https://wwwn.cdc.gov/nchs/nhanes/ analyticguidelines.aspx (accessed May 4, 2018).

(71) WHO, World Health Organization (WHO). Global Physical Activity Questionnaire (GPAQ) analysis guide. Available at www.who. int/chp/steps/resources/GPAQ Analysis_Guide.pdf (accessed May 4, 2018). 